Editorial

\title{
Plastic Deformation, Microstructure, and Residual Stress in Metal Joining for Light Weighting
}

\author{
Rezwanul Haque ${ }^{D},{ }^{1}$ Ayodele Olofinjana, ${ }^{1}$ and Benjamin Imasogie ${ }^{2}$ \\ ${ }^{1}$ University of the Sunshine Coast, Sunshine Coast, Australia \\ ${ }^{2}$ Obafemi Awolowo University, Ife, Nigeria \\ Correspondence should be addressed to Rezwanul Haque; rhaque@usc.edu.au
}

Received 22 April 2020; Accepted 22 April 2020; Published 5 May 2020

Copyright (C) 2020 Rezwanul Haque et al. This is an open access article distributed under the Creative Commons Attribution License, which permits unrestricted use, distribution, and reproduction in any medium, provided the original work is properly cited.

Manufacturing industries throughout the world are constantly facing the pressure to reduce carbon emissions. The aerospace and automobile industries strategy for reducing carbon emissions is inherently centred around selection of designs and materials aimed at reducing the overall weight. Most common approaches to light-weighting have been based on clever selection of materials that suggests using engineered light alloys: titanium, magnesium, and aluminium and hybrid materials such as fibre-reinforced composites with high strength-to-weight ratios.

Since by design, engineering devices are multicomponent, and combining materials in design to achieve lightweight requires the need to understand how well new and different materials can fit to meet the functional (especially structural) properties. Joining of materials in lightweight designs has, therefore, become a topical issue [1]. There is still a lot of research to be performed to address the challenges that come with methods for joining because of the rapid introduction of new lightweight alloys in designs of components. The issues facing the joining of dissimilar materials, such as ceramics to metals [2], composite to metal $[3,4]$, two dissimilar metals $[5,6]$, constantly need to be addressed. Many joining techniques that are fusion-based $[1,7]$ and mechanical fastenings [3] that have been proposed are promising, but the accompanying severe plastic deformation and the microstructural modifications that typically attend joints for both fusion and mechanical joining processes can potentially cause problems and need to be addressed. Consequently, the mechanical condition of the joint-affected zone needs to be studied well especially the propensity for the development of residual stresses. A continuous development of innovations is required to achieve the goal of efficient joining methods for newly developed lightweight materials that covers the commonly used candidates: Ti-Al-V [2], Mg-Zn [6], and Al- alloys [7] and fibre-reinforced plastics (FRP) $[3,4]$.

The objective of this special issue is to collate manuscripts addressing significant developments and innovations in research and overview of technology for joining and combination of dissimilar materials in engineering components to achieve improved performance and lightweight. In this special issue, the published papers addressed several issues relating to light-weighting that included (1) joining of dissimilar materials, (2) microstructure-property relationships in deformation processing, (3) combination of materials to achieve optimum engineering functions, and (4) application of computational methods in manufacturing.

Magnesium (Mg) alloys because of its low specific gravity, are currently attracting attention for light-weighting designs especially in transport machines where the target is to reduce energy consumption. $\mathrm{Mg}-\mathrm{AZ}$ alloy series [8] were originally designed to be shaped by casting, but as new alloys are being introduced, the need for deformation shaping has increased. Q. Yang et al. studied the deformation behaviour of an $\mathrm{Mg}$ alloy during high temperature compression. They reported the effects of processing parameters on the hot forming of $\mathrm{Mg} \mathrm{AZ} 31$. Their work indicated the importance of flow stress and its relationship with forming temperature. They provided evidence of grain growth that resulted from dynamic recrystallization at $500^{\circ} \mathrm{C}$. 
Ti-6Al-4V alloys are the prime candidate material in many lightweight designs because of their very high specific stiffness (modulus-to-density ratio). Their microstructures depend so much on processing and structure-processing relationship, which is a topical issue. X. Fang et al. studied the microstructural behaviour of Ti-6Al-4V alloy due to severe plastic deformation. Their study provides insight into the effects of forging temperature on the microstructure of Ti-6Al-4V alloys. It was highlighted that the microstructural homogeneity is enhanced by the dynamic plastic deformation. The problem of joining Ti-6Al-4V to other components is important in the lightweight research. A. Sharma and $\mathrm{B}$. Ahn addressed the topical issue of metal ceramic fusion bonding with the study of braze joining of Ti-6Al-4V with zirconia $\left(\mathrm{ZrO}_{2}\right)$ by developing a new filler material based on Ag-Cu-Ti ternary alloy. Improved wettability of the filler material leading to stronger joints was achieved by the addition of specific amount of nanosized ceria (0.05 wt.\% $\mathrm{CeO}_{2}$ ) particles.

L. Fan et al. studied the effect of precision forming on the quality of submerged arc-welded pipes. They developed an analytical method to predict the spring-back in real time in order to develop precision forming by crimping. D. Lv et al. also studied the issue of a drill pipe joint which provides connection, transformation, and transmission of torque for high-speed drilling in the petroleum industry. The effects of $\mathrm{Al}-\mathrm{Zn}$ coatings on the adhesive strength, morphology of microstructure, and corrosion resistance were studied.

X. Li et al. analysed different strength factors of a conveyor belt where a joint between the steel rope and rubber was obtained by an adhesive layer. They employed computational methods to analyse the integrity of the conveyor belt splices.

Aluminium is another candidate material often used for light weight. Its uses with other structural materials made joining a topical issue. Y. Ge and Y. Xia addressed the dynamic behaviour of dissimilar joints of aluminium and steel sheets for both self-piercing riveting and mechanical clinching process. Their study concluded that the joint strength can be significantly improved by prestraining through baking process.

The compilation of papers in this special issue covers a wide range of issues relating to innovations and research development in the use of lightweight and addressing processing issues. It is hoped that they will generate more interest that will spring more discussions on this and other related issues.

\section{Conflicts of Interest}

The guest editors declare that there are no conflicts of interest involved in this special issue.

\section{Acknowledgments}

The editors would like to thank the authors for their excellent contributions. The editors also want to express their gratitude to the reviewers for their support during the review process by providing constructive criticism to improve the quality of the papers in a timely manner.

Rezwanul Haque
Ayodele Olofinjana
Benjamin Imasogie

\section{References}

[1] J. Chen, E. Salvati, F. Uzun et al., "An experimental and numerical analysis of residual stresses in a TIG weldment of a single crystal nickel-base superalloy," Journal of Manufacturing Processes, vol. 53, pp. 190-200, 2020.

[2] Y. Gao, L. J. Huang, Y. Bao et al., "Joints of TiBw/Ti6Al4V composites- Inconel 718 alloys dissimilar joining using $\mathrm{Nb}$ and $\mathrm{Cu}$ interlayers," Journal of Alloys and Compounds, vol. 822, 2020.

[3] N. Z. Borba, J. Korbelin, B. Fiedler, J. F. dos Santos, and S. T. Amancio-Filho, "Low-velocity impact response of friction riveted joints for aircraft application," Materials \& Design, vol. 186, 2020.

[4] E. Petersen, J. Koord, O. Volkerink, D. Stefaniak, and C. Huhne, "Experimental and numerical investigation of the transition zone of locally steel-reinforced joining areas under combined tension-bending loading," Journal of Composite Materials, 2019, In press.

[5] H. Vemanaboina, G. Edison, and S. Akella, "Validation of residual stress distributions in multipass dissimilar joints for GTAW process," Journal of Engineering Science and Technology, vol. 14, no. 5, pp. 2964-2978, 2019.

[6] X. Y. Gu, C. L. Sui, J. Liu, D. L. Li, Z. Y. Meng, and K. X. Zhu, "Microstructure and mechanical properties of $\mathrm{Mg} / \mathrm{Al}$ joints welded by ultrasonic spot welding with $\mathrm{Zn}$ interlayer," $\mathrm{Ma}$ terials \& Design, vol. 181, 2019.

[7] P. H. Shah and V. J. Badheka, "Friction stir welding of aluminium alloys: an overview of experimental findings-process, variables, development and applications," Proceedings of the Institution of Mechanical Engineers, Part L: Journal of Materials: Design and Applications, vol. 233, no. 6, pp. 1191-1226, 2019.

[8] S. J. Chen, X. Wang, T. Yuan, and X. X. Li, "Research on prediction method of liquation cracking susceptibility to magnesium alloy welds," Acta Metallurgica Sinica, vol. 54, no. 12 , pp. $1735-1744,2018$. 